\title{
Monoclonal Antibody HuAFP31
}

National Cancer Institute

\section{Source}

National Cancer Institute. Monoclonal Antibody HuAFP31. NCI Thesaurus. Code C48407.

A humanized monoclonal antibody directed ag ainst alpha fetoprotein with potential antineoplastic activity. Upon administration, monoclonal antibody HuAFP31 (mAb HuAFP31) binds to and stimulates a cytotoxic T lymphocyte (CTL) response against tumor cells that express alpha fetoprotein. 